\title{
Soy lo que descuido el presidente: sobre percursos e resistências nos acolhimentos institucionais
}

\author{
Soy lo que descuidó el presidente: sobre recorridos y resistencias en los acogimientos \\ institucionales
}

Soy lo que descuidó el presidente: on pathways and resistance in institutional sheltering

\author{
Amanda Cappellari \\ Universidade de Santa Cruz do Sul - Rio Grande do Sul - Brasil
}

Betina Hillesheim

Universidade de Santa Cruz do Sul - Rio Grande do Sul - Brasil

\section{RESUMO}

O presente artigo objetiva discutir a construção de verdades a respeito de jovens que se encontram sob medida de proteção. Para tanto, analisou-se prontuários referentes a 10 jovens que foram acolhidos entre os anos 2015 e 2016, sendo que o critério de inclusão para a produção de dados foi de que tais jovens, além de terem passado pelo abrigo, também foram atendidos, em algum momento, pelo Centro de Atenção Psicossocial da Infância e Adolescência (CAPSIA). A pesquisa realizada bifurca-se em dois movimentos: mostrar a construção de verdades que encerram biografias de jovens nas quais tudo já está previsto e, por outro lado, assinalar que as lacunas dos prontuários, bem como sua profusão de prescrições e encaminhamentos, também apontam para a composição de outras forças, dobrando as prescrições e buscando a escrita do que se denominou poemas-vida. Para realizar tal discussão, a partir dos dados dos prontuários, utilizou-se a trajetória de um dos jovens, buscando visibilizar tais jogos de força.

Palavras-chave: Medidas de proteção. Acolhimento. Verdade. Juventude.

\section{RESUMEN}

El presente artículo tiene el objetivo de discutir la construcción de verdades respecto a jóvenes que se encuentran bajo medida de protección. Para ello, se han analizado prontuarios referentes a 10 jóvenes acogidos entre los años 2015 y 2016. El criterio de inclusión para la producción de datos fue que los jóvenes, además de haber pasado por el albergue, también recibieron atención, en algún momento, en el Centro de Atenção Psicossocial da Infância e Adolescência (CAPSIA). La investigación se despliega en dos movimientos: mostrar la construcción de verdades que encierran biografías de jóvenes en las que todo ya está previsto y, por otro lado, señalar que las lagunas de los prontuarios, y asimismo su profusión de prescripciones y encaminamientos, también señalan la composición de otras fuerzas, duplicando las prescripciones y buscando la escritura de lo que se ha denominado 
poemas-vida. Para realizar dicha discusión a partir de los datos de los prontuarios, se ha utilizado la trayectoria de uno de los jóvenes, buscando visibilizar esos juegos de fuerza.

Palabras-clave: Medidas de protección. Acogimiento. Verdad. Juventud.

\begin{abstract}
This article aims to discuss the construction of truths regarding adolescents under protection measures. Therefore, medical reports of 10 adolescents sheltered from 2015 to 2016 were analyzed. The inclusion criterion for the production of data was that the adolescents, in addition to having passed through the sheltering institution, were also attended, at some point, by the Centro de AtençãoPsicossocial da Infância e Adolescência (CAPSIA) [Center for Psychosocial Care of Children and Adolescents]. The study conducted is divided into two movements: first, to show the construction of truths that contain biographies of adolescents in which everything is already foreseen; on the other hand, to point out that the gaps in the medical reports, as well as their profusion of prescriptions and referrals, also indicate the composition of other forces which end up doubling the prescriptions and seeking the writing of what has been called life-poems. In order to carry out a discussion from the data of the medical reports, the trajectory of an adolescent was used as a means to make such power games visible.
\end{abstract}

Keywords: Protection measures. Sheltering. Truth. Youth.

Este não é um livro de história. A escolha que nele se encontrará não seguiu outra regra mais importante do que meu gosto, meu prazer, uma emoção, o riso, a surpresa, um certo assombro ou qualquer outro sentimento, do qual teria dificuldades, talvez, em justificar a intensidade, agora que o primeiro momento da descoberta passou. É uma ontologia de existências (Foucault, 2003a, p. 203).

São de "vidas singulares, tornadas, por não sei quais acasos, estranhos poemas" que discorre Foucault (2003a, p. 204) no texto $A$ vida dos homens infames. São também de poemas-vida que se ocupa o presente artigo, conforme inspirado pelo texto do filósofo francês. Dez jovens-poemas-vida rasurados pelo acolhimento institucional, sendo que, para melhor compreendê-los, foi-se em busca de outras narrativas de suas histórias. São, portanto, dez poemas-vida que foram acolhidos institucionalmente nos anos de 2015 e 2016, cujas estrofes foram construídas e declamadas pela passagem em um Centro de
Atenção Psicossocial da Infância e Adolescência (CAPSIA). Assinala-se a escolha do uso do termo juventude, pois, conforme discutido por Silva e Lopes (2009), essa denominação considera os processos sociais como fundamentais para compreender a juventude como uma categoria social, considerando as tensões e pressões presentes no contexto social em que se inserem.

O termo poemas-vida adquire,neste texto, alguns sentidos. A palavra poema deriva do verbo grego, poein, significando fazer, criar ou construir ${ }^{1}$. Poemas-vida porque belos, porque contam uma história. Poemas-vida porque compõem suas histórias junto às políticas públicas, sendo que, se não fosse feito tal arranjo, provavelmente não saberíamos de suas existências. Para Cândido (1996), dois elementos importantes de um poema são a sonoridade e o ritmo, que estão intimamente interligados. $\mathrm{O}$ ritmo, mais especificadamente, "seria a expressão de uma regularidade que fere e agrada os nossos

1

http://origemdapalavra.com.br/site/palavras/poesia/ , recuperado em 11 de junho de 2017 
sentidos" (p. 43). Poemas-vida, portanto, que se aproximam pela semelhança de suas histórias, mas que compõem sonoridades e ritmos singulares, capazes de ferir e/ou agradar os sentidos.Contudo, poemas-vida, também por suas existências "obscuras e desventuradas" (Foucault, 2003a, p. 204). Poder-se-ia dizer: mais obscuras do que belas, em sua maioria. Ora, mas poemas não expressam também sofrimentos, dores, despedidas e saudades? E sua beleza não residiria justamente nisso?

Assim como no texto de Foucault (2003a), as histórias desses jovens só puderam se tornar visíveis no momento em que uma luz, que só existe a partir de um encontro específico - no caso, com as políticas públicas voltadas à infância e à adolescência, iluminouas. "É o encontro com o poder: sem esse choque, nenhuma palavra, sem dúvida, estaria ali para lembrar seu fugidio trajeto"(p. 207). Entretanto, se a vida dos homens infames é marcada pelo encontro com o poder de um monarca, o poder que encontra os jovenspoemas-vida desse trabalho é um poder "constituído de uma rede fina, diferenciada, contínua, na qual se alternam instituições diversas" (p. 219). Poder que circula, que se exerce na relação, ação sobre ações possíveis, que incita, produz, potencializa forças, sendo que essas vidas, no encontro com o poder "se debatem com ele, tentam utilizar suas forças ou escapar de suas armadilhas" (p. 208), tornando-se visíveis e narráveis.

Sabe-se da existência dos jovenspoemas-vida que compõem esse trabalho, especialmente,pelo encontro com o poder exercido pelas políticas públicas de saúde, educação, assistência social e segurança. Mas são nos ofícios redigidos e recebidos pela instituição de acolhimento que se encontram espécies de biografias, histórias de vida oficiadas. Por vezes, quando solicitado o acolhimento institucional pelo Conselho Tutelar (CT), encontra-se no pedido um certo $q u e ̂$ de dossiê: a biografia do jovem-poemavida, expressa até seus mais ínfimos detalhes, que justifiquem a medida protetiva. Ínfimos não por serem desnecessários, mas no sentido de sua pequenez, que, aliada ao discurso psi, sustentam o lugar de verdade e postulam a necessidade do acolhimento institucional. Entende-se aqui 'discursos psi' como aqueles advindos de um conjunto de saberes voltados para o entendimento de uma suposta interioridade do sujeito: a Psiquiatria, a Psicologia, a Psicanálise, a Psicossociologia, etc.Nesse sentido, os profissionais psique tiveram contato com os jovens-poemas-vida também são chamados a escrever, não com os mesmos, mas sobre eles. Assim, a psicologia, ao ser convocada a traçar biografias e diagnósticos, "encontra no domínio sobre a história de vida dos sujeitos a condição de possibilidade para se tornar um saber necessário no campo da segurança" (Hadler, 2017, p.57) e o elemento biográfico acaba por se constituírem um conjunto de práticas que, aliadas a determinado campos, se tornam um saber sobre os sujeitos.

Dessa maneira, este texto se fundamenta em uma pesquisa na qual foram analisados os prontuários de jovens acolhidos institucionalmente em um abrigo de uma cidade de médio porte, localizada no interior do Rio Grande do Sul, nos anos de 2015 e 2016, e que haviam também passado por atendimento no Centro de Atenção Psicossocial da Infância e Adolescência. Seguindo esse critério, analisaram-se 20 prontuários de 10 adolescentes (seus prontuários no abrigo e seus prontuários no CAPSIA). $O$ foco da pesquisa foram os motivos dos acolhimentos, quem solicitou o recurso, quais as estratégias de cuidado efetuadas antes do acolhimento e de que modo as famílias das crianças ou dos jovens acolhidos institucionalmente são narrados a partir dos prontuários. A partir da visualização de suas trajetórias e construção das narrativas, no presente artigo busca-se discutir, em um primeiro momento, como os prontuários, mediante suas prescrições, produz trajetórias.Após, escolheu-se uma das trajetórias dosjovens para problematizar as verdades construídas pelo encontro dessa vida com o poder, ressaltando seus movimentos de 
resistência e a constituição de um jovempoema-vida.

Ressalta-se que, na discussão realizada, o que está em questão, seguindo os passos de Foucault (2010), não é o quê o ou o porquê, mas o como: uma análise que se inicia pelo como não busca a essência do poder, mas parte da suspeita da complexidade da realidade, buscando estabelecer as relações que fazem que as coisas se ocorram de determinada maneira e não de outra, mediante uma investigação crítica sobre as formas pelas quais o poder opera. Trata-se, portanto, de uma interrogação que se volta não para como as coisas se manifestam, mas como o poder se exerce.

\section{Sobre Prontuários e Produção de Verdades}

Foucault (2013), ao discorrer sobre o que denomina poder disciplinar, isto é, um poder que se exerce sobre o corpo dos indivíduos, mediante uma multiplicidade de processos mínimos, pontua que alguns mecanismos entraram em cena para que melhor se pudesse conhecer e mensurar os diversos aspectos da vida dos sujeitos. Um desses mecanismos de controle normalizante diz respeito à técnica do exame, que trouxe consigo todo um aparato de escrita, afim de uma "vigilância que permite qualificar, classificar e punir" (p.177).Nesse sentido, o exame possibilita documentar a individualidade mediante uma rede de anotações que visam captar e fixar os sujeitos, através de um poder que incide diretamente sobre os corpos.

Nessa perspectiva, deve-se destacar a centralidade do que Foucault (2006) denominou como função-psi. Para o autor, tal função compreende não apenas o discurso (psiquiátrico, psicopatológico, psicocriminológico, psicanalítico, etc.), mas a própria ideia de um indivíduo psicológico, sendo que seus agentes se articulam à organização de um dispositivo disciplinar que se precipita na lacuna deixada pela família:

A função-psi nasceu, portanto, dessa espécie de par em relação à família, a família requeria o internamento; o indivíduo era posto sob disciplina psiquiátrica e devia-se refamiliarizálo. Depois, pouco a pouco, a funçãopsi se estendeu a todos os sistemas disciplinares: escola, exército, oficina, etc. Vale dizer que essa função-psi desempenhou o papel de disciplina para todos os indisciplináveis" (p. 106).

No enlace de práticas e discursos entre psicologia e segurança, Reis, Guareschi e Carvalho (2014) assinalam que os laudos e relatórios traçam uma categoria populacional e não a história de uma vida singular. É como se a linguagem técnica utilizada, marcada pela padronização e repetição de alguns modelos, fizesse parecer que se fala sempre de um mesmo sujeito. Assim, a referida pesquisa aponta a presença de uma categoria populacional de jovens abrigados, como se coubessem a todos as mesmas práticas e as mesmas decisões sobre acolher ou não acolher.

Foucault (2006) ressalta que a propriedade fundamental do poder disciplinar é a fabricação de corpos sujeitados: trata-se de um poder individualizante que ajusta a funçãosujeito à singularidade do corpo, mediante um sistema de vigilância constante, de escrita/exame, de punições, de projeção de uma determinada interioridade, do estabelecimento da norma e de uma instância normalizadora. Tal função-sujeito, isto é, a emergência de um corpo subjetivizado, é que possibilita que surja algo que como a ideia de indivíduo.

A constituição de sujeito, portanto, está relacionada à produção de verdade. Para Foucault (2003b), as produções de verdade estão vinculadas aos mecanismos de poder, pois são esses que dão as condições de existência para tais produções.Ainda para o autor (2001), em nossa sociedade, os discursos de verdade se fundamentam em um estatuto de cientificidade, sendo que a alguns é dada a legitimidade de proferi-los. 
Ao pensar sobre os jovens que estão no abrigo, essa condição se legitima a partir da noção de proteção integral que está prevista no Estatuto da Criança e Adolescente (ECA), o qual, em seu artigo 98, trata das medidas de proteção:

As medidas de proteção à criança e ao adolescente são aplicáveis sempre que os direitos reconhecidos nesta Lei forem ameaçados ou violados: I - por ação ou omissão da sociedade ou do Estado; II - por falta, omissão ou abuso dos pais ou responsável; III em razão de sua conduta. (Brasil, 1990, s.p.)

Mais adiante, por ocasião da constituição do Sistema Único de Assistência Social, em 2004, estão previstos dois níveis de proteção: básica e especial. Enquanto a primeira visa à prevenção do risco, mediante o desenvolvimento de potencialidades e fortalecimento de vínculos, a proteção social especial se direciona às famílias e indivíduos considerados em situação de risco (Carlson; Pinheiro, 2013).

Nascimento (2014) sublinha que, na contemporaneidade, o desejo de proteção é afirmado como um modo subjetivo: "desejar proteção é desejar segurança e justiça, fabricação social e histórica que imprime à proteção a condição de ser intensamente desejada no presente" (p. 460). A proteção é vista, assim, como um bem absoluto e necessário, o qual justifica qualquer prática entendida como protetiva. Dessa maneira, a autora propõe pensar os funcionamentos da proteção como uma estratégia biopolítica, a qual opera tanto sobre as famílias em particular, quanto na população como um todo.

Frente a esse discurso da proteção, que se coloca como uma verdade, o acolhimento é visto como uma alternativa relacionada à salvaguarda desses jovens. Entretanto, pode-se inverter a questão: proteção de quem? Afinal, como alerta Foucault (2012), em nome da proteção social, os imperativos do Estado podem facilmente ser ativados. Em defesa da sociedade, portanto, pela proteção, determinadas práticas - entre as quais, nesse artigo, destaca-se o acolhimento de jovens vistos como necessitados de proteção social especial - são justificadas e naturalizadas.

\section{Soy lo que Descuidó El Presidente: A Narrativa de um Jovem-Poema-Vida}

O trabalho com os prontuários evidencia as verdades produzidas a respeito dos jovens sob proteção: cada um dos prontuários reveste a vida desses jovens numa multiplicidade de ofícios, os quais buscam explicar, descrever e, especialmente, dar encaminhamentos às situações dos mesmos. As biografias estão fragmentadas em tantos ofícios diferentes, que se faz necessário um insistente e exaustivo trabalho de leituras e releituras afim de traçar um certo fio condutor para que suas histórias sejam inteligíveis. $\mathrm{Na}$ junção desses fragmentos, observa-se que mediante a escolha seletiva do que é registrado nos prontuários, são construídas justificativas tanto para o acolhimento quanto para outras medidas que são entendidas como necessárias. Entretanto, as lacunas deixadas pelos prontuários podem dar espaço a outras possibilidades, não fechando todos os caminhos.

Conforme Hadler (2017) pode-se compreender que, se o discurso é uma prática que produz determinadas verdades, essas biografias também podem transbordar: não que se localizem num fora da escritura, mas se encontram no limiar da palavra, ou seja, constituem-se como biografias elementares, que se tornam movimento frente aos regimes de verdade e aos jogos de forças. A partir disso, tais biografias são denominadas como malditas, isto é, biografias que não se constituem através de informações que demandem atos de verificação, mas que atualizam a relação entre a psicologia e a segurança, deixando de estarem circunscritas a esses domínios e dando visibilidade às 
diferentes relações de força e jogos de verdade que as produzem.

Nesse sentido, aproximando-se as noções de biografias malditas e literatura menor, conceito desenvolvido por Deleuze e Guattari (1977), é possível pensar que talvez seja justamente nas lacunas biográficas entre um ofício e outro(s), que os poemas-vida podem se fazer potência e minorar, mal-ditos no sentido de que não é tudo dito. Assim, como assinalam Deleuze e Parnet (1998), trata-se de fazer a língua gaguejar, lhe impondo outros usos que não aqueles utilizados pela maioria. Dessa maneira, talvez sejam nesses interstícios, nesse caminho entre uma página e outra, que se encontram brechas para resistir às imposições do que se espera desses jovens. Se, por um lado, as instituições buscam, incessantemente, recobrir de palavras essas vidas, tudo explicando, nos prontuários há visíveis gagueiras: idas e vindas, informações desencontradas, mal-dizeres.

Nessa perspectiva, entre os vinte prontuários analisados, destaca-se, nesse artigo, o percurso de um dos jovens, vida dividida entre dois prontuários: do CAPSIA e do abrigo. $\mathrm{O}$ encontro desse jovem com o poder ocorre pela suspeita de uso de substâncias psicoativas. Aos 10 anos, é encaminhado ao CAPSIA pelo Conselho Tutelar. É acolhido pelo serviço, passa por consulta psiquiátrica e tem indicação para oficina terapêutica. Frequenta um projeto de assistência no turno inverso da escola. Decorrido um ano, é solicitado o acolhimento institucional, devido à situação de risco e vulnerabilidade social pelo uso de drogas e das dificuldades no cuidado por sua família, acrescidas das faltas à escola e ao tratamento no serviço de saúde. O pedido de acolhimento é negado.

Após seis meses, suspeitando-se de envolvimento com o tráfico, o jovem passa por internação compulsória. Quando retorna para casa, é acompanhado também pela Estratégia de Saúde da Família (ESF) e pelo Centro de Referência em Assistência Social (CRAS), dando-se continuidade ao seu tratamento no
CAPSIA. Em menos de um mês, nova internação. E, no mesmo dia de sua alta, concorda em ir para uma Unidade de Acolhimento Infanto-juvenil (serviço que oferece acolhimento transitório para crianças e adolescentes com problemas devido ao uso de substância psicoativas),onde reside por 6 meses. Durante os períodos de internação recebe visitas da família e de alguns profissionais ligados ao seu tratamento, enquanto sua biografia é discutida por uma vasta rede de serviços: CAPSIA, ESF, CRAS, Conselho Tutelar, escola...

Após a internação, o jovem é colocado na família dos tios, onde permanece por pouco mais de um mês, retornando para a casa da mãe e da avó, que é quem se responsabiliza por ele. Nesse momento, nova internação e nova solicitação para acolhimento institucional, o qual é deferido. Porém, evade o abrigo e retorna à casa da avó. Diante da situação, o CRAS encaminha a família para acompanhamento no Centro de Referência Especializado em Assistência Social (CREAS) e lhe oferta aulas de violão. Conduzido novamente ao abrigo, evade por incontáveis vezes. Nesse período, é encaminhando para uma avaliação neurológica.

Após um mês, ocorre nova internação, agora com pelo menos 3 ou 4 mandados de busca e apreensão, já que está desaparecido por mais de 20 dias. Da internação, é encaminhado à Comunidade Terapêutica e, durante o tratamento, a rede se articula para providenciar que, por ocasião da alta, fosse enviado para outra instituição de tratamento de drogadição. Entretanto, ele não concorda com o novo encaminhamento e é acolhido novamente pelo abrigo, sendo enviado para diversas atividades no CAPSIA, onde deve passar parte do dia. O período que se seguiu é marcado por novas evasões, até que, em audiência, é decidido que volte a residir com a avó, passe por avaliação na APAE, siga com o tratamento no CAPSIA e participe de oficinas de convivência no CRAS.

Nessa perspectiva, pode-se compreender a rede - CRAS, abrigo, 
CAPSIA, APAE, CREAS, etc. - como uma imensa malha que busca capturar vidas, trazêlas para mais perto, fixá-las, dobrá-las ao poder. Nessa vida capturada pelas políticas públicas, no intuito de protegê-lo e garantir seus direitos básicos, também operam no sentido de conduzir sua conduta, produzindo nele um desejo outro que não o de viver e habitar daquele modo, considerado perigoso, moldando-o a padrões tido como aceitáveis. Destaca-se o papel dos saberes psi que colaboram com a produção da discursividade sobre jovens em situação de vulnerabilidade, ao apontá-los como sem perspectivas de futuro, ainda mais quando envolvidos com drogas. A emergência da noção de que esses jovens estariam desprovidos de autocontrole assegura ações baseadas na disciplina e na contenção como possibilidades para o cuidado (Scisleski; Reis; Hadler; Assis Brasil; Guareschi,2012).

Além disso, pode-se problematizar a própria articulação que se dá, continuamente, entre proteção e segurança: Nascimento (2014) aponta que, nessa rede, as famílias são vigiadas, policiadas, ameaçadas e denunciadas, sendo que tais ações são realizadas por pessoas próximas (vizinhos, parentes, professores, profissionais de diferentes serviços...). Nesse mecanismo, a denúncia ocupa um papel decisivo no sentido de colocar em funcionamento a máquina judiciária, constituindo-se como uma prática de produção de verdade apoiada no discurso da proteção. Pela denúncia, cria-se um sentimento de dever cumprido, permitindo que a consciência cidadã se apazigue e se organizem redes de vigilância que pressupõem que existe um modo de viver correto, o qual será garantido pelo judiciário.

$\mathrm{O}$ ato de denunciar o outro às autoridades competentes, aos profissionais especializados, ao judiciário, na maioria das vezes de modo anônimo, ajusta-se com precisão ao jogo da judicialização, porque é visto como uma prática de defesa da lei, uma prática que sustenta uma moral de retidão, de justiça. (Nascimento, 2014, p. 462)

Diante das investidas de cuidado e proteção, pode-se perceber que o jovem concorda com algumas idas e vindas, recusa outras, e, por vezes, parece não ter opção de escolha. Contudo, conforme Foucault (2010, p. 289), "não há relação de poder onde as determinações estão saturadas (...). Não há, portanto, um confronto entre poder e liberdade, numa relação de exclusão (onde quer que o poder se exerça, a liberdade desaparece), mas um jogo muito mais complexo", isto é, a liberdade é pré-condição para o exercício do poder. Dessa maneira, poder e resistência tem uma relação de avesso: "falar do avesso não significa se referir a um outro lado, nem a algo por trás, escondido. $\mathrm{O}$ avesso constitui-se como o mesmo lado, algo a ser revirado, exposto, escancarado" (Hillesheim, 2008, p. 93). Não seriam, assim, suas inúmeras evasões, modos de resistência? Soy lo que descuido el presidente, cantam Mercedes Sosa e René Pérez, e, pode-se pensar que esses pequenos descuidos (não no sentido de falha das políticas, mas em seus deslizes) possibilitam que o jovem escreva um poema-vida, encontrando sua potência.

Um delinquente arrisca sua vida contra castigos abusivos; um louco não suporta mais estar preso $\mathrm{e}$ decaído; um povo recusa o regime que o oprime. Isso não torna $o$ primeiro inocente, não cura o outro $\mathrm{e}$ não garante ao terceiro os dias prometidos. Ninguém, aliás, é obrigado a ser solidário a eles. Ninguém é obrigado a achar que aquelas vozes confusas cantam melhor do que as outras e falam da essência do verdadeiro. Basta que elas existam e que tenham contra elas tudo que se obstina em fazê-las calar, para que faça sentido escutá-las e buscar o que elas querem dizer. (Foucault, 2004a, p. 80)

As lacunas nos prontuários, os reiterados movimentos das equipes dos 
diferentes serviços, as inúmeras tentativas de garantir a fixação do jovem, apontam para o que Hadler (2017) denomina como um maldizer, ou seja, um dizer que não consegue encerrar as biografias em previsíveis finais. Dessa maneira, pode-se pensar que, pelo gaguejar dos prontuários, a vida, como sugerido pela autora, não pode ser possuída, representada ou dita: "todavia, maldita; quando os mal-dizeres são as forças que não encerram em finais decisivos. É assim que se tornam biografias malditas: uma composição a partir de fragmentos e memórias espectrais, que insurgentes amaldiçoam certeiros finais" (p. 82).

Aquilo que pode ser interpretado como descuido ou falha da rede, possibilita linhas de fuga: o jovem evade. Fugir, dizem Deleuze e Parnet (1998, p. 30), "não é renunciar às ações, nada mais ativo que uma fuga. É o contrário do imaginário. É também fazer fugir, não necessariamente os outros, mas fazer alguma coisa fugir, fazer um sistema vazar como se fura um cano", fugir, portanto, "é produzir algo real, criar vida, encontrar uma arma" (p. 40). O que o sistema lê como evasões do jovem, pode ser visto como linhas se fuga,flexionando os modos pelos quais tentam capturá-lo, docilizá-lo; fazendo vibrar as técnicas de poder existentes, exigindo que essas também se movimentem, criem alternativas que considerem seu modo de existência.

Diz Foucault (2008, p. 96): “o problema dos que governam não deve ser absolutamente o de saber como eles podem dizer não (...); o problema é o de saber como dizer sim". A resistência do jovem, conduz o exercício do poder ao seu limite. "No centro da relação de poder, 'provocando-a' incessantemente, encontra-se a recalcitrância do querer e a intransitividade da liberdade" (Foucault, 2010, p. 289).Em meio a esse jogo de forças, o jovem retorna à casa da avó e outros modos de vigilância são acionados (avaliação na APAE, tratamento no CAPSIA, oficinas de convivência no CRAS). Nesse jogo de forças não há vencedores, o que existe é um jogo marcado por constantes tensões que se provocam mutuamente.

\section{Considerações Finais}

A pesquisa realizada bifurca-se em dois movimentos: mostrar a construção de verdades que encerram biografias de adolescentes nas quais tudo já está previsto e, por outro lado, assinalar que, se como postula Foucault (2010), não há poder sem resistência, as lacunas dos prontuários, bem como sua profusão de prescrições e encaminhamentos, também apontam para a composição de outras forças, dobrando as prescrições e buscando a escrita de um poema-vida. Salienta-se ainda que não se pretende realizar julgamentos sobre as práticas efetuadas pelos serviços, mas problematizar as verdades produzidas sobre os jovens e as medidas de proteção. Entende-se problematização como "o conjunto de práticas discursivas ou não-discursivas que faz alguma coisa entrar no jogo do verdadeiro e do falso e o constitui como objeto para o pensamento (Foucault, 2004b, p. 242).

Frente à leitura de cada nova página que costurava os acontecimentos da vida dos jovens que passaram pelo abrigo, emerge o desassossego que antes já borbulhava. Ao ler, invade-se a vida do outro? Intromete-se nela? Eis que se inicia um longo e constante processo de perder e produzir sentidos de pesquisa, que desemboca em uma perguntainquietação: como fazer uma pesquisa que não seja sobre o outro, mas que também possa ser escrita com ele?

Para Deleuze e Parnet (1998), "ao escrever sempre se dá escritura a quem não tem, mas estes dão à escritura um devir sem o qual ela não existiria, sem o qual ela seria pura redundância a serviço das potências estabelecidas" (p. 57). Nesse sentido, "a escritura encontra sempre uma minoria que não escreve, ela não se encarrega de escrever para essa minoria, em seu lugar, e tampouco sobre ela, mas há encontro onde cada um empurra o outro, o leva em sua linha de fuga (...)” (p. 57). Não sendo possível, portanto, escrever com os adolescentes e negando uma pesquisa que seja sobre eles, exercita-se 
flexionar o pensamento no sentido de "traçar linhas de fuga, que não são imaginárias, que se é forçado a seguir, porque a escritura nos engaja nelas, na realidade, nos embarca nela" (p. 35).

Nesse exercício de pensamento, problematiza-se as intervenções realizadas em nome da proteção, visto que, como afirma Nascimento (2014), muitas vezes, o fato de alguma criança ou jovem não pertencer a uma família que atenda aos modelos préestabelecidos, justifica uma intervenção do Estado, retirando-lhes a possibilidade de viver em suas famílias em favor de acolhimentos "tão questionáveis quanto as práticas familiares interditadas" (p. 465). Além disso, a prática da denúncia, produzida como algo importante e necessário numa sociedade marcada pelo sentimento de medo e insegurança, universaliza determinados modos de ser e estar no mundo, acionando a lei para regular formas de viver diferenciadas. Como exemplo dessas diferentes formas de viver, pode-se citar as pesquisas de Fonseca (2006) sobre a circulação de crianças em bairros populares de Porto Alegre, prática essa que, analisada sob a ótica das classes médias urbanas acaba sendo conceituada como abandono, mas que, para essas famílias, se constitui como estratégia de sobrevivência.

Dessa maneira, entende-se que essa pesquisa, ao buscar pela vida que se embrenha em meio aos laudos e ofícios frios que povoam os prontuários, evidencia que as resistências dos jovens alvos das políticas de proteção, longe de ser entendidas como negativas, são produtivas no sentido de limitar o exercício do poder, criando outras possibilidades.

\section{Referências}

Brasil (1990). Estatuto da Criança e do Adolescente. Lei 8.069, de 13 jul. 1990. Diário Oficial da República Federativa do Brasil. Brasília/DF.

Cândido, A. (1996). O estudo analítico do poema. 3 ed. São Paulo: Humanitas Publicações/FFLCH/USP.
Carlson, A. C. R.; Pinheiro, L. de S. (2013). Práticas intersetoriais: novos desafios postos aos psicólogos na atual política de assistência social. In: Cruz, L. R. \&Guareschi, N. M. de. Interlocuções entre a psicologia e a política nacional de assistência social (pp. 103-116). Santa Cruz do Sul: EDUNISC. Recuperado em 12 junho de 2017, de https://craspsicologia.files.wordpress.com/2 013/03/interlecuc3a7c3b5es-entre-apsicologia-e-a-pnas.pdf

Deleuze, G.\& Guattari, F.(1977). Kafka: por uma literatura menor. Rio de Janeiro: Imago. (Original publicado em 1975).

Deleuze, G. \& Parnet, C.(1998). Diálogos. São Paulo: Escuta. (Original publicado em 1977).

Fonseca, C. (2006). Da circulação de crianças à adoção internacional: questões de pertencimento e posse. Cad. Pagu, Campinas , 26, 11-43. Recuperado em 12 setembro de 2017, de http://www.scielo.br/scielo.php?script=sci arttext\&pid=S0104$\underline{83332006000100002 \& \operatorname{lng}=\mathrm{en} \& \mathrm{nrm}=\mathrm{iso}}$

Foucault, M. (2013). Vigiar e punir. Nascimento da prisão. 41 ed., Petrópolis: Vozes. (Original publicado em 1975). . (2012). A estratégia do controle.

In Foucault, M. Ditos e Escritos VIII. Segurança, penalidade e prisão (pp. 133136). Rio de Janeiro: Forense Universitária. . (2010). O sujeito e o poder. In:

Dreyfus, H. L. \&Rabinow, P. Michel Foucault. Uma trajetória filosófica (pp. 273-295). 2 ed. Rio de janeiro: Forense. . (2008). Segurança, Território, População. São Paulo: Martins Fontes. . (2006). O poder psiquiátrico. São

Paulo: Martins Fontes. . (2004a). É inútil revoltar-se? In:

Foucault, M. Ditos e escritos $V$. Ética, sexualidade e política (pp. 77-81). Rio de Janeiro: Forense Universitária. (2004b). O cuidado com a verdade. In: Foucault, M. Ditos e escritos $V$. Ética, sexualidade e política (pp.240251). Rio de Janeiro: Forense Universitária. 
(2003a). A vida dos homens

infames. In: Foucault, M. Ditos e escritos $I V$. Estratégia, poder-saber (pp. 203-222). Rio de Janeiro: Forense Universitária. (2003b). Poder e saber. In:

Foucault, M. Ditos e escritos IV. Estratégia, poder-saber (pp. 223-240). Rio de Janeiro: Forense Universitária. (2001). Os anormais. São Paulo:

Martins Fontes.

Hadler, O. H. (2017). Biografias malditas: experiências narrativo ontológicas entre psicologia e segurança. Tese de Doutorado, Programa de Pós-Graduação em Psicologia Social e Institucional do Instituto de Psicologia da Universidade Federal do Rio Grande do Sul,Porto Alegre, RS.

Hillesheim, B. (2008). Entre a literatura e o infantil. Uma infância. Porto Alegre: Abrapso-Sul.

Nascimento, M. L. (2014). Pelos caminhos da judicialização: lei, denúncia e proteção no contemporâneo. Psicol. estud., 19 (3), 459467. Recuperado em 12 setembro de 2017, de

http://www.scielo.br/scielo.php?script=sci arttext\&pid $=$ S141373722014000300011\&lng=en\&nrm.

Reis, C.; Guareschi, N.; M. F.\& Carvalho, S. (2014). Sobre jovens drogaditos: as histórias de ninguém. Psicologia \& Sociedade, 26 (n. spe.), 68-78. Recuperado em 9 junho de 2017, de http://www.scielo.br/pdf/psoc/v26nspe/08.p df.

Scisleski, A. C. C.; Reis, C.; Hadler, O. W.; M. de A. B.\& Guareschi, N. M. de F. (2012). Juventude e pobreza: a construção de sujeitos potencialmente perigosos. Arquivos Brasileiros de Psicologia, 64(3), 19-34. Recuperado em 11 de junho de 2017, de http://pepsic.bvsalud.org/scielo.php?script= sci_arttext\&pid=S180952672012000300003\&lng=pt\&tlng=p.

Silva, C. R; Lopes, R. E. (2009). Adolescência e juventude: entre conceitos e políticas públicas. Cadernos de Terapia Ocupacional da UFSCar, São Carlos, juldez, 17 (2), 87-106. Recuperado em 11 setembro de 2017 , de

http://www.cadernosdeto.ufscar.br/index.ph $\mathrm{p} /$ cadernos/article/viewFile/100/65.

Dados sobre as autoras:

- Amanda Cappellari é acadêmica de Psicologia (UNISC), bolsista de Iniciação Científica (FAPERGS).

- Betina Hillesheim é Doutora em Psicologia (PUCRS), professora do departamento de Psicologia e do Programa de Pós-Graduação em Educação (UNISC), bolsista produtividade em pesquisa nível $2(\mathrm{CNPq})$. 